\title{
Research on Clothing Rental Model under Sharing Economy
}

\author{
Xiaoyao $\mathrm{Mu}^{1}$ and Chenggang $\mathrm{Li} * 2$ \\ Beijing Institute of Fashion Technology School of Business Hunan, China \\ Professor, Vice Dean Beijing Institute of Fashion Technology School of Business Beijing, China
}

\begin{abstract}
In recent years, the emergence of various clothing rental platforms makes the clothing rental model has been well applied. Based on the premise of the rapid development of sharing economy, this paper discusses the necessity of clothing rental model in the boom of sharing economy. Based on the analysis of the investment scale, profit growth rate, operation mode and industry structure of the garment rental mode, this paper illustrates the problems of this mode in the supply side, transaction cost, health and safety and market positioning, and then puts forward the strategies to solve these problems.
\end{abstract}

\section{Introduction}

In recent years, sharing economy, a new economic model, has been widely applied under the environment of rapid development of the Internet. The term "shared wardrobe" has emerged as a result of the sharing economy. The essence of a shared wardrobe is the clothing rental model, which was developed decades ago. In the Internet era, clothing rental model develops rapidly. Nowadays, people can rent different styles of clothes they like more quickly and conveniently. We can see this from many apps such as YiErSan and Goddess Pai. In fact, although the model has been developed, it is still in the exploratory stage.

In this paper, I will discuss the fashion trend of clothing rental mode, deeply analyze how to find its own broad space in the era of sharing economy, and put forward suggestions for the development of this mode.

\section{RESEARCH STATUS OF DOMESTIC CLOTHING RENTAL MODEL}

In recent years, a lot of research has been done on clothing rental model in China.

With the booming of the new economic model of sharing economy in the market, Research on the Application of Sharing Economy in the Clothing Field [1] analyzes the development status of the clothing rental industry in the context of the rise of sharing economy. Research on Problems and Countermeasures of Clothing Sharing in the Sharing Economy [2] puts forward the reasons for the slow development of the clothing rental industry through field visits and opening of clothing rental shops. Research on the Development Status and Development Strategy of China's Clothing Rental Platform comprehensively put forward the development strategy of clothing rental mode [3]. In Research on the Influence and Trend of the New Retail Business Model on the Change of Consumption in the Garment Market [4], the author puts forward the view of online and offline coherent brand service. Exploring the Business Model of Renters in the Shared Economy [5] applies the theory to practice, mainly showing the business layout of the business model of "Renters" in the face of numerous problems existing in the clothing rental model.

To sum up, from the perspective of the development history of clothing rental mode, domestic researches generally present a progressive trend.

\section{THE NECESSITY OF THE DEVELOPMENT OF CLOTHING RENTAL MODEL UNDER THE SHARED ECONOMY}

In 2020, China Sharing Economy Development Report (2021) released by the State Information Center pointed out that the market transactions of the sharing economy in China were about 3,377.3 billion yuan, with a year-on-year growth of about $2.9 \%$, and the direct financing scale of the sharing economy was about 118.5 billion yuan, with a sharp year-on-year growth of $66 \%$ [6]. According to the data, the market size of the sharing economy has grown substantially, and the new business model of sharing economy consumption can be expected in the future.

(I) It is necessary to build a green ecological civilization

The important function of sharing economy is to integrate idle resources. Combined with the clothing rental model, it is not difficult to find that if the idle clothing resources in the society are integrated and recycled twice, it will greatly avoid clothing waste and maximize the value of a piece of clothing. In today's

*Corresponding author: Chenggang Li, ccid205@126.com 
increasingly bad ecological environment and serious lack of water resources, the natural advantage of green and environmentally friendly clothing rental mode is conducive to the construction of ecological civilization and the promotion of sustainable economic development. It is urgent to improve the waste of clothing resources, and perhaps the clothing rental model can bring us ideas.

\section{(II) The need to innovate new business models}

Haring economy plays a pivotal role in promoting the innovation of new business models. The new retail clothing business model integrates online and offline, aiming to improve customers' consumption experience and product interaction. The theoretical model of the new retail clothing business model (see Figure 1) is also applicable to the clothing rental model.

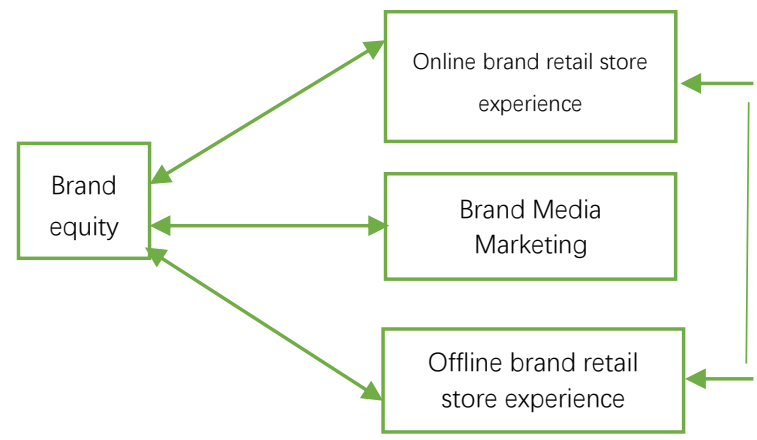

Fig. 1 The influence model of the new retail business model on the change of consumption in the model clothing market

According to the above theoretical model, through the analysis of clothing rental mode, when media marketing or online rental experience is enhanced or weakened, consumers' perception and recognition of clothing rental will change accordingly. At the same time, online rental experience and media marketing also affect offline rental experience, which exactly determines the possibility of offline development of clothing rental model. Enhancing benign media marketing, enhancing online clothing rental experience, and carrying out online and offline clothing rental at the same time not only greatly speeds up information transmission and communication, but also poses a new challenge to the new operation mode of innovative offline clothing rental.

(III) The need to improve the efficiency of the economy

With the rapid development of the sharing economy, "connection", the main element of the sharing economy, enables the supply side and the demand side to be rapidly connected through the Internet, thus greatly improving the efficiency of economic operation. At the first Global Sharing Economy Forum, Ge Jun, CEO of Tianju Sharing Group, said that the great sharing economy will bring about a double improvement in resources and efficiency, that is, global consumption of new resources will be reduced by 50 percent, and people's working hours will be reduced by 50 percent. The current garment rental model relies on the Internet, and is different from the traditional garment rental model in that the idle resources in the former are rapidly connected between the supply side and the demand side, with high resource utilization efficiency and low transaction cost.

\section{ANALYSIS OF THE STATUS QUO OF CLOTHING RENTAL MODEL}

\section{(I) Investment scale}

From 2016 to 2018, major clothing leasing platforms have completed various financing. As shown in Figure 2, the financing scale of Elysee Group accounted for $42 \%$, while that of Doraemon Group and Goddess Group accounted for $31 \%$ and $27 \%$, respectively[7]. However, after 2019, financing for the garment rental industry under the sharing economy is scarce, and many garment rental platforms have withdrawn from the market due to improper management. At present, the garment rental industry investment scale has been greatly reduced, the market size is shrinking, and only a few start-up companies are still in operation. Garment rental mode ushered in the cold winter, the ice-breaking remodeling is expected to expand the current market scale of the garment rental industry.

\section{Table of financing proportion of clothing leasing platform \\ 4 \\ - Ycloset - The goddess PAI - Doraemon}

Figure 2: Pie chart of financing scale of clothing leasing platform

\section{(II) Profit growth rate}

The profit growth rate of the garment rental industry is not balanced due to the problems such as the rapid change of fashion trend, the difficult way of washing and the high cost of express delivery. At present, a number of clothing rental platforms have achieved overall profits under the condition of improving their operating models, but the profit space is not large, and the profit growth rate is still on the upward trend of slow fluctuations. In order to enhance their profit growth, the major platforms implement the rental and sales model; At the same time to improve customer performance credibility, expand the scale of products. These measures are aimed at broadening the way to make money, changing the problem of a single point of profit and attracting a wide range of potential users. It is speculated that in the next few years, the clothing rental industry is expected to achieve profitability exponential growth, to achieve profitability scale.

\section{(III) Mode of operation}

Look at a number of domestic clothing rental platform, they are based on the membership monthly subscription model, single dress rental as a supplement. This mode of operation has the advantages of improving consumer stickiness, improving clothing life cycle and expanding profit space, but it also has disadvantages. First, the member's rights and interests are less, which cannot meet the multiple needs of consumers. Second, 
the audience group is small and limited to the white-collar class with strong affordability; Can not avoid some consumers to earn clothing price difference and not return the phenomenon of wool.

\section{THE REMAINNING PROBLEMS IN THE CLOTHING RENTAL MODEL}

In fact, the garment rental industry has evolved from a red sea to a Dead Sea economy in the past few years, which is closely related to the unsolved problems in the garment rental model.

\section{(I) Supply and demand cannot be matched}

In the clothing rental industry, the common ways of clothing supply in the market include cooperation with brand parties and design by self-owned brand clothing designers. Figure 3 shows a simple clothing rental process. When middlemen purchase brand clothing and produce designer clothing, they often encounter the problem that clothing supply and consumer demand cannot be connected, that is, outdated clothing styles and fewer sizes of existing goods cannot meet consumers' differentiated, personalized and appropriate clothing needs. The reason is that the overall functional requirements of the leasing platform have not been deployed and planned according to the involved consumer groups, and the construction of the platform ecosystem has not been perfected [8].

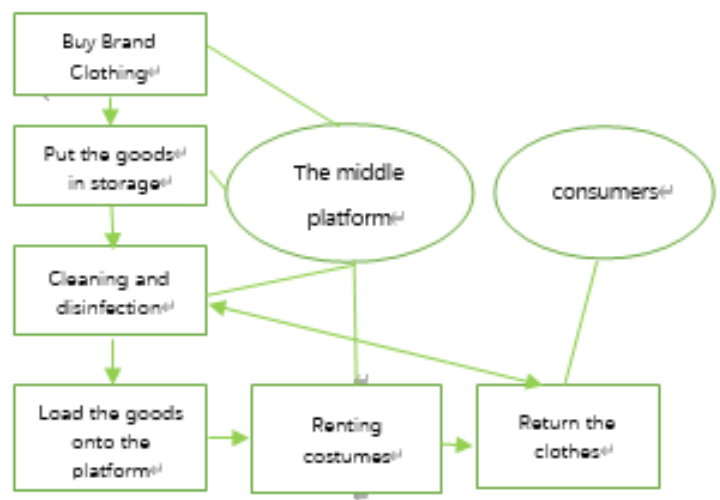

Figure 3: Clothing rental mode flow chart

\section{(II) High transaction costs}

In fact, the development of garment rental industry often encounters the problems of high transaction costs and small profit margins.

In the procurement process, raw material manufacturers need to purchase a large number of common clothing styles and expensive gowns, the procurement cost is often higher than expected, coupled with the warehouse capacity is not enough to accommodate excessive goods, which determines that the warehouse cost must be increased. In logistics links, costume rental platform is not effective to control logistics cost, logistics activities in a state of out of control [9], the cost is not to maximize use, which will directly lead to logistics development is not balanced ecosystem.

(III) Narrow market positioning
The current clothing rental platform mainly locates the market among young white collars. When the income of white collars is fully measured, the acceptance degree of this part of the population to the clothing rental mode is also considered, that is, the attitude of contemporary young people to downplay the relationship between ownership and right of use. However, if we want to make the clothing rental model universal, only targeting at young white-collar workers will limit the horizontal development of the market, which will lead to too narrow market positioning and fail to give full play to the advantages of environmental protection, ecology, science and sustainability of the model.

\section{(IV) Industry structure}

At present, the garment rental industry structure is mainly composed of raw material manufacturers, service intermediaries and consumers.

Raw material manufacturers are mainly responsible for the procurement and production of upstream clothing products; Service intermediaries are the major garment rental platforms, which provide services, products and users, plan the future development of the garment rental industry and predict the growth trend of the platform; Consumers are the experiencers of various resources provided by service intermediaries. They generate profits for the garment rental industry and play a decisive role in improving the production mode and business model of the industry. Raw material manufacturers, service intermediaries and consumers complement each other and link inside and outside, which strongly supports the industry structure of internal supply and external demand in the garment rental mode.

\section{CLOTHING SHARING RENTAL MODEL DEVELOPMENT STRATEGY}

According to the above problems, it is of great significance to discuss the future development space of the clothing rental model and put forward long-term development strategies, which is of great significance to innovate new forms of clothing business and promote the transformation of the clothing industry.

(I) Adjust clothing supply chain

In order to connect the supply side with the demand side, the garment rental industry must promote the reform of the garment supply side.

We will integrate production with consumption and adjust the supply structure. The new concept of integration of production and consumption has been realized in such concrete forms as consumption capitalization, production-sales alliance, and co-creation of value [10], which plays an important role in adjusting the clothing supply chain. Consumer capitalization can integrate consumers and clothing rental platform, which is equivalent to consumers investing in the supply link of clothing when they rent, so that producers and consumers can have the necessary connection, so that the supply side and the demand side can have a harmonious connection.

(II) Reduce transaction costs 
The transaction cost problem is particularly prominent in the application of garment rental mode in the garment industry.

First, clothing hoarding keeps the transaction costs of the platform high. A number of clothing rental platforms launched second-hand clothing mall, that is, the strategy of renting and selling together. To a large extent, this marketing strategy has solved the problems such as the inability to circulate clothes with multiple turnover, hoarding goods and occupying warehouses in large areas, and low profits. At the same time, the platform can open offline stores of different sizes for the sale of hoarding clothes, and build a point-to-level second-hand clothing rental market.

Second, the cost of various transportation links is high, and logistics management lags behind. The establishment of logistics information management system and the improvement of regional transportation construction can reduce the transaction cost and release the vitality of logistics. At the same time, in its own development, the clothing rental logistics system can learn from Jingdong Express and establish a specialized express service of its own platform to reduce logistics and transportation costs.

(III) Ensure the hygiene and safety of clothing

Clothing rental focuses on regular service rental, which directly faces the problem of long time of regular service, high probability of close to the body, and clothing hygiene and safety determine the experience of consumers when renting. The development of the model and entrepreneurs in the health and safety issues must establish a complete clothing cleaning system, such as clothes 23 launched warehouse washing with intelligent integration, 16 cleaning procedures are essential. After cleaning, carry out health and safety inspection on each garment, and then continue to put it on the rental platform.

The construction of perfect clothing cleaning measures is the foundation, improve customer trust and loyalty is the focus. Open the whole cleaning process of clothing to consumers, so that the whole process is "transparent and verifiable"; Clothing in every rental after the health inspection results are updated at any time on the platform, break the psychological barrier of consumers, to achieve real peace of mind, rest assured.

\section{(IV) Expand market positioning}

The garment rental industry should step by step for different income groups, focus on middle and low income

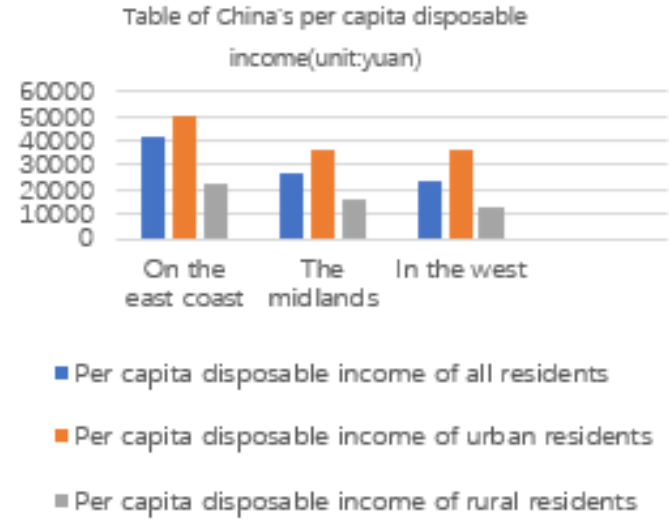

Figure 4: China's per capita disposable income table in 2020(Note: According to the data of per capita disposable income of residents in 31 provinces and municipalities in 2020)

groups, give full consideration to their economic strength, and form different modes of platform rental strategies.

According to the per capita disposable income in 2020 released by the National Bureau of Statistics, we know that the per capita income in the eastern coastal areas of China reached 41,176 yuan, while the central and western regions only reached 27,284 yuan and 23,726 yuan, respectively. Therefore, the per capita disposable income in most areas of China is generally low, and the feasibility of a monthly subscription model with a monthly fee of at least 499 yuan is not very high. Facing the high membership fee, consumers do not buy it. For this part of the population, the platform should change its operation mode, such as the multi-piece clothing package rental mode, and implement the policy that the more pieces, the greater the preferential intensity. At the same time, a deposit of $50 \%$ of the price is set to avoid the phenomenon of wool collecting.

To sum up, the clothing rental model can target the middle and low-income groups in the vast eastern, central and western urban areas, and its market features are: low rental cost, wide coverage and citizenization.

\section{(V) Strengthen advertising marketing}

Garment rental mode has a small position in the garment industry, but its popularity is not high and its application scope is not wide. To strengthen advertising marketing and let the clothing rental model into the public view can truly reflect the practicality of this model. The Journal of Advertising Marketing puts forward the strategies to strengthen advertising marketing: Incitation, Emotion, Visualization, Value of Use, Story. Incentives are marketing strategies that make consumers associate and imagine a certain product under a specific environment and thus generate purchase desire, such as the connection between diamonds and marriage. In the development of clothing rental mode, we can set up some incentives, and match the incentives with the mode, so as to achieve the effect of "changing colors because of talk". In visualization, this term originally refers to the process of displaying data on the screen using computer image processing technology. In this paper, it refers to presenting the clothing rental mode to 
the public and creating public opinion to attract attention. When this mode is visualized, people's concerns will be widely gathered. The stronger the public opinion, the more concentrated people's attention will be.

\section{CONCLUSION}

Today, with the rapid development of the sharing economy, the clothing rental model plays an important role in the construction of ecological civilization, the promotion of economic operation efficiency and the innovation of new business models. After analyzing the current situation and problems of the garment rental mode, this paper puts forward the strategies of developing the garment rental mode. It is believed that in today's era of changing science and technology, the model will be developed and mature rapidly, and it is only a matter of time. There are endless possibilities in the clothing rental model, waiting to be explored.

\section{ACKNOWLEDGMENT}

Fund Project: In 2021, Beijing Institute of Fashion Technology Undergraduate Innovation and Entrepreneurship Training Program Project - Feasibility Study of Clothing Exchange and Leasing Mode under the Shared Economy Environment.

Beijing Social Science Foundation - Capital Garment Culture and Garment Industry Research Base Project Research on Intelligent Business Form Innovation of Beijing Fashion Culture Industry (19JDYJA007)

\section{REFERENCES}

1. Wang Wei, Zhou Yi. Chemical Fiber \& Textile Technology,2016,45(04):27-31. (in Chinese)

2. Li Rong, Fan Ziling. Research on Problems and Countermeasures of Clothing Sharing in Sharing Economy [J]. Journal of Taiyuan City Vocational and Technical College,2018(05):38-39.

3. Wang Bei, Zhou Yang, Si Xingyu, Zhang Shangyan, He Lingyue. Research on the development status and development strategy of apparel rental platform in China $[\mathrm{J}]$. Light Textile Industry \& Technology,2020,49(05):72-74.

4. Jia Wen. Research on the Influence and Trend of New Retail Business Model on the Change of Clothing Market Consumption [J].Liaoning Economy,2019(07):48-50.

5. Li Shuai, Zhu Yingjie. Exploring the business model of renter under the sharing economy [J]. Think Tank Times,2017(09):68+246.

6. National Information Center. China Sharing Economy Development Report (2021) [R]. Sharing Economy Research Center.2021-2-19.

7. Zhao Na. Sharing Economy Attack: Can Online Clothing Renting Bring Closet Revolution [J]. Decision Exploration (First Half),2017(03):42-43.
8. Zhao Wei, Zhang Yingqing, Zhang Renkai, Peng Li. Design and Implementation of Campus Clothing Rental Service Platform Based on WeChat Small Program [J]. Computer Knowledge and Technology,2020,16(21):8-9+12.

9. Ren Xiaoying. Research on Manufacturing Logistics Cost Accounting Method -- Independent Logistics Accounting Analysis [J].Industrial Innovation Research,2020(07):55-56.

10. Meng Qingchun, Cao Chen, Ma Shuo. Research on the concept of integration of new production and consumption $\quad[\mathrm{J}]$. Theoretical Journal,2014(05):39-42+129. 